\title{
The Seasonal Health Questionnaire is more effective at detecting seasonal affective disorder than the Seasonal Pattern Adjustment Questionnaire
}

Thompson C, Thompson S, Smith R. Prevalence of seasonal affective disorder in primary care; a comparison of the seasonal health questionnaire and the seasonal pattern assessment questionnaire. J Affect Disord 2004;78:219-26.

\section{Q Is the Seasonal Health Questionnaire or the Seasonal Pattern Adjustment Questionnaire a better tool to screen for seasonal affective disorder?}

\section{METHODS}

Design: Prospective cohort study.
Setting: Two general medical practices, Southampton, UK;
Patients: 803 people, aged $>26$ years, randomly selected at
excluded.
$\begin{aligned} & \text { Test: Seasonal Pattern Assessment Questionnaire (SPAQ); } \\ & \text { disorder was diagnosed automatically from completed } \\ & \text { questionnaires according to ICD-10, DSM-III-R, and DSM-IV } \\ & \text { criteria. } \\ & \text { Diagnostic standard: Structured Clinical Interview for DSM-III-R } \\ & \text { (SCID). A trained psychiatrist blinded to the study results assessed } \\ & 56 \text { participants. } \\ & \text { Outcomes: Sensitivity and specificity of tests; positive and } \\ & \text { negative predictive value; prevalence of seasonal affective } \\ & \text { disorder. }\end{aligned}$

\section{MAIN RESULTS}

The SHQ has greater sensitivity, specificity, and positive and negative predictive value when screening for seasonal affective disorder than the SPAQ (see table). The prevalence of seasonal affective disorder

Table Sensitivity, specificity, positive and negative likelihood ratios for each test

\begin{tabular}{lll}
\hline & SPAQ & SHQ \\
\hline Sensitivity \% (95\% Cl) & $38(0.2$ to 0.6$)$ & $59(0.4$ to 0.8$)$ \\
Specificity \% (95\% Cl) & $79(0.6$ to 0.9$)$ & $97(0.9$ to 1.0$)$ \\
$\begin{array}{l}\text { Positive predictive value \% } \\
\text { (95\% CI) }\end{array}$ & $53(0.3$ to 0.8$)$ & $93(0.7$ to 1.0$)$ \\
$\begin{array}{l}\text { Negative predictive value \% } \\
\text { (95\% CI) }\end{array}$ & $67(0.5$ to 0.8$)$ & $79(0.6$ to 0.9$)$ \\
\end{tabular}

For correspondence: Chris Thompson, Community Clinical Sciences Research Division, University of Southampton, Royal South Hants Hospital, Brinton's Terrace, Southampton, UK; ctl@soton.ac.uk

Sources of funding: none specified. predicted using the SHQ was lower than predicted with the SPAQ (SHQ: $5.6,95 \%$ CI 4.2 to 7.4 ; SPAQ: $10.7,95 \%$ CI 8.6 to 13.1 ).

\section{CONCLUSIONS}

SHQ is more appropriate than SPAQ for identifying people with seasonal affective disorder.

\section{Commentory}

D iagnoses similar to seasonal affective disorder (SAD) were made literally thousands of years ago, and the diagnosis was resurrected by Rosenthal et al in 1984.' Rosenthal's group published the Seasonal Pattern Assessment Questionnaire ${ }^{2}$ (SPAQ) three years later, largely based on their own diagnostic criteria. Since then, the SPAQ has been by far the most commonly used screening instrument for SAD. Much of what we think we know about the epidemiology of SAD derives from population screening studies using the SPAQ. The SPAQ's low specificity in diagnosing $S A D$ is its major weakness, with less than half of SPAQ cases satisfying more rigorous diagnostic criteria in most studies. The SPAQ has thus contributed to an overestimation of the prevalence of SAD and through this, almost certainly, to its being taken less seriously than it merits by professionals working in psychiatry.

In this context, the Seasonal Health Questionnaire (SHQ) constitutes a step forward. It has identified a much more realistic prevalence of SAD among primary care attenders than the SPAQ which it out performs in both specificity and sensitivity in this study. The original publication of the $S H Q^{3}$ found the SPAQ to be more sensitive when compared against diagnoses by experienced clinicians. In the current study, the gold standard diagnosis was through a SCID interview, which is based on DSM-IIIR diagnostic criteria. As the SHQ is also partly based on DSM-IIIR, its superior performance might be regarded as something of a selffulfilling prophecy. Its basis upon sensible, narrow diagnostic criteria is, of course, also one of the instrument's major strengths. Although the SHQ is more complex than the SPAQ, patients do not seem to have difficulty completing it ${ }^{3}$ and in the present study $78 \%$ of patients managed to do so while waiting to see their general practitioner.

The case for the SHQ now becoming the primary screening tool for SAD has been adequately made. Currently, SAD very often goes unrecognised and untreated ${ }^{4}$; a more robust screening instrument which diagnoses a more realistic prevalence of sufferers may help to improve this situation.

Dr John M Eagles, MPhil, FRCPsych Consultant Psychiatrist, Royal Cornhill Hospital, Aberdeen, UK

1 Rosenthal NE, Sack DA, Gillin JC, et al. Seasonal affective disorder: a description of the syndrome and preliminary findings with light therapy. Arch Gen Psychiatry 1984;41:72-80.

2 Rosenthal NE, Genhart M, Sack DA, et al. Seasonal affective disorder: relevance for treatment and research of bulimia. In: Hudson JL, Pope HG eds. Psychobiology of bulimia. Washington DC: APA, 1987:205-8.

3 Thompson C, Cowan A. The Seasonal Health Questionnaire: a preliminary validation of a new instrument to screen for Seasonal Affective Disorder. $J$ Affect Disord 2001;64:89-98.

4 Eagles JM, Howie FL, Cameron IM, et al. Use of health care services in seasonal affective disorder. Br J Psychiatry 2002;180:449-54. 